\title{
Treatment of central giant cell lesions using bisphosphonates with intralesional corticosteroid injections
}

\author{
Newton Guerreiro da Silva Júnior ${ }^{1}$, Aline Semblano Dias Carreira ${ }^{1,4^{*}}$, Erick Nelo Pedreira ${ }^{2}$, Fabrício Mesquita Tuji ${ }^{1}$, \\ Karem López Ortega $^{3}$ and João de Jesus Viana Pinheiro ${ }^{2}$
}

\begin{abstract}
Central giant cell lesions are benign intraosseous proliferative lesions that have considerable local aggressiveness. Nonsurgical treatment methods, such as intralesional corticosteroid injections, systemic calcitonin and interferon have been reported. Recently, bisphosphonates have been used to treat central giant cell lesions. A case of a 36-year-old male with a central giant cell lesion crossing the mandibular midline was treated with intralesional corticosteroids combined with alendronate sodium for the control of systemic bone resorption. The steroid injections and the use of bisphosphonates were stopped after seven months when further needle penetration into the lesion was not possible due to new bone formation. After two years, the bony architecture was near normal, and only minimal radiolucency was present around the root apices of the involved teeth. The patient was followed up for four years, and panoramic radiography showed areas of new bone formation. Thus far, neither recurrence nor side effects of the medication have been detected.
\end{abstract}

Keywords: Giant central granuloma, Nonsurgical management, Corticosteroids, Bisphosphonates

\section{Background}

Central giant cell lesions (CGCLs) are benign intraosseous proliferative lesions that occur in the maxilla and mandible primarily during the first to third decades of life [1]. Histologically, multinucleated giant cells are prominent throughout the fibroblastic stroma and are often clustered around areas of haemorrhage [2].

CGCLs represent a treatment challenge. The clinical behaviour is extremely variable in that certain lesions are completely silent and grow very slowly whereas others behave more aggressively [3]. In recurrent or aggressive lesions, en bloc resection is a treatment option, but this procedure results in large surgical defects $[4,5]$. Nonsurgical treatment methods, such as intralesional corticosteroid injections and systemic calcitonin or interferon- $\alpha$, are increasingly being used [4,6-11].

\footnotetext{
* Correspondence: alinecarreira@hotmail.com

${ }^{1}$ School of Dentistry, Federal University of Pará-UFPA, Avenida Augusto Corrêa, 01, Belém, PA 66075-110, Brazil

${ }^{4}$ Faculdade de Odontologia, Instituto de Ciências da Saúde, Universidade Federal do Pará, Avenida Augusto Corrêa, 01, Belém, PA 66075-110, Brazil Full list of author information is available at the end of the article
}

Steroids appear to inhibit the production of extracellular lysosomal proteases in multinucleated giant cells. In addition, steroids reduce bone resorption and induce the apoptosis of osteoclastic cells [5].

Bisphosphonates are widely used to inhibit osteolysis in conditions such as osteoporosis, Paget's disease and bone destruction through metastatic cancer. Landesberg et al. [1] reported three cases of CGCLs treated with bisphosphonates. The first case showed the successful treatment with a single administration of intravenous bisphosphonates, the second resulted in a 30\% reduction of the lesion, and the last case showed stabilisation but no regression of the lesion.

Based on such evidence, the purpose of this study was to report a case of CGCL that had been treated with intralesional corticosteroids and oral bisphosphonates.

\section{Report of a case}

A 36-year-old male with no relevant medical history was referred for the evaluation of swelling on the left side of his jaw, which had been associated with paraesthesia for the previous 5 months. On extra-oral examination, a

\section{Biomed Central}




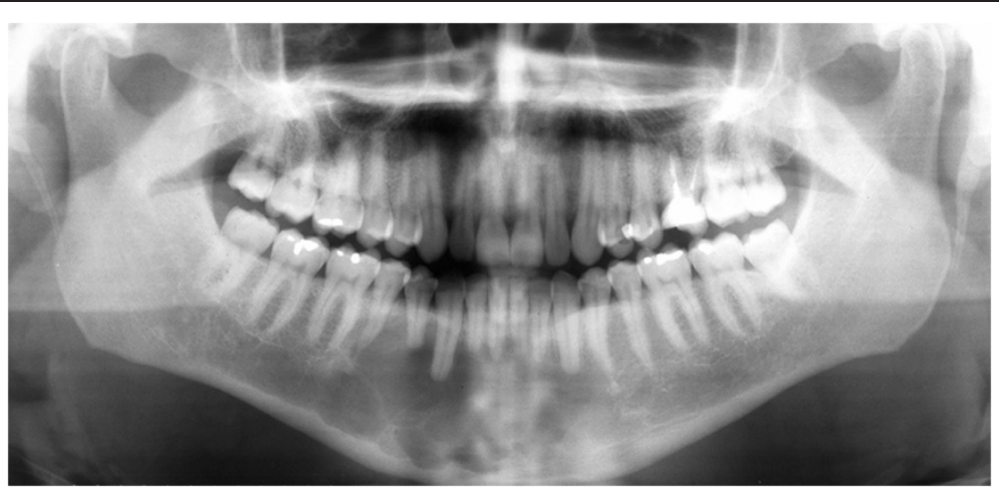

Figure 1 A Panoramic radiography. A multilocular radiolucent area crossing the midline and causing resorption in certain teeth.

slight swelling in the chin region was noted. Intraorally, the examination revealed swelling of the mouth vestibule and high tooth mobility.

Panoramic radiographs showed a multilocular radiolucent area in the anterior mandible extending from tooth 36 to tooth 45, causing the resorption of certain teeth (Figure 1). A computed tomography (CT) scan showed that the lesion crossed the midline and extended to the inferior border of the mandible. In addition, there was an expansion of the buccal and lingual cortices with consequent disruption. The mandibular canal on both sides and the mandibular foramen on the left side were compromised (Figure 2).

An incisional biopsy was performed, which showed multinucleated giant cells surrounded by a disorganised stroma with intense inflammatory infiltrates. There were mainly mononuclear infiltrates with numerous haemorrhagic areas and viable bone tissue surrounding the lesion. Based on these characteristics, the final diagnosis was CGCL (Figure 3).

The results of blood tests were normal, and after ruling out the possibility of the injury being associated with hormonal disorders (hyperparathyroidism), the proposed treatment was intralesional infiltration of triamcinolone, similar to the protocol described by Terry and Jacoway [12]. Such infiltrations are typically recommended to be performed weekly for six weeks at multiple sites of the lesion $[5,6,9]$.

In this case, a $1 \mathrm{ml}$ ampoule of Theracort (triamcinolone acetonide, $40 \mathrm{mg} / \mathrm{ml}$ ) diluted in $3,6 \mathrm{ml}$ of $2 \%$ mepivacaine (epinephrine 1:100,000) was used. The patient received 10 injections, seven of which were given over a period of approximately 15 days and the remaining three injections over the course of one month. The corticosteroid solution was more concentrated in a specific area of the lesion in each infiltration. After the first injection, the anaesthetic solution was replaced by $3 \%$ mepivacaine (without epinephrine) because the patient was tachycardic during infiltration even when the procedure was performed slowly for approximately five minutes.

Alendronate sodium $(70 \mathrm{mg}$ ) was used on a weekly basis to control bone resorption during treatment. Additionally, oral calcium carbonate $(500 \mathrm{mg}$ ) was administered daily to facilitate the calcification of the lesion. The treatment

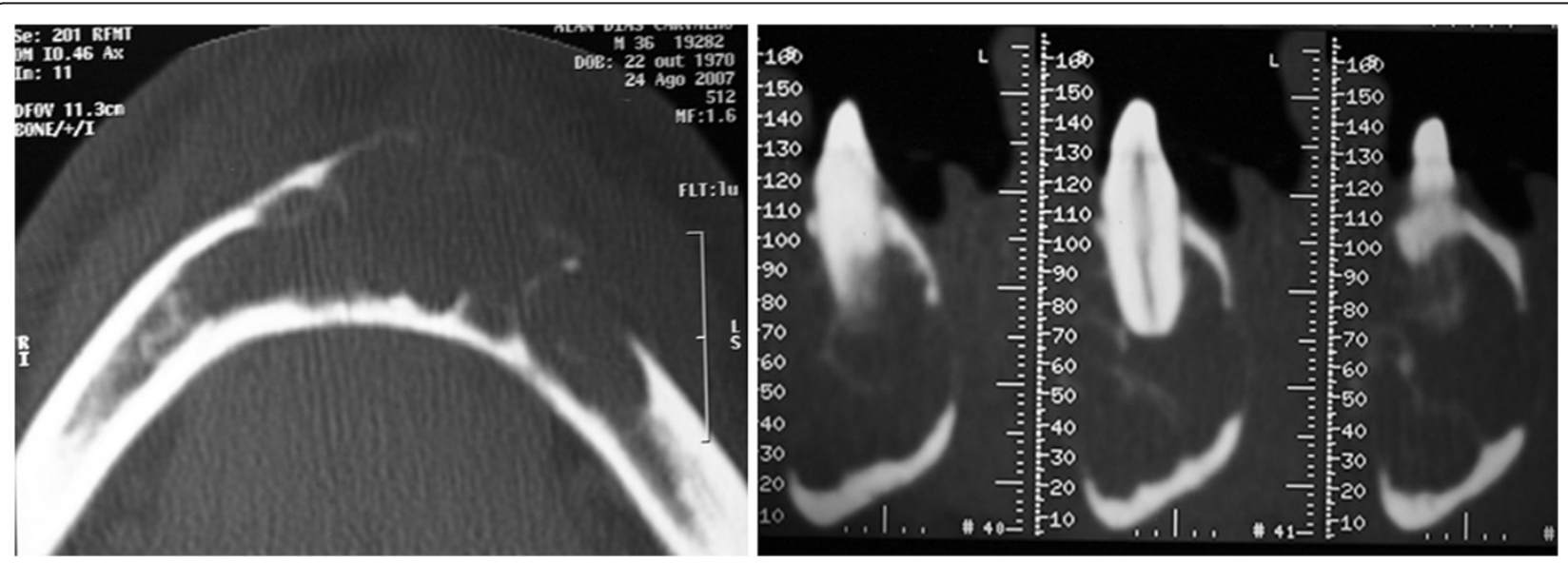

Figure 2 Computed tompography scan. The expansion of the buccal and lingual cortices with consequent disruption. 


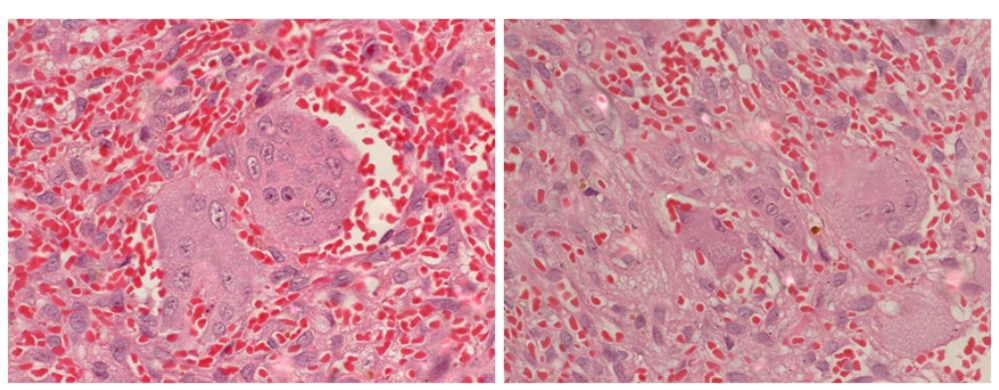

Figure 3 Histological sections stained with H.E. The presence of multinucleated giant cells surrounded by a disorganised stroma with an intense inflammatory infiltrate.

lasted seven months, after which further needle penetration into the lesion was not possible due to new bone formation. The administration of alendronate sodium and calcium carbonate was suspended at the same time.

After two years, the bony architecture was near normal and only minimal radiolucency was present around the root apices of the involved teeth. Both the cortical and the drilling areas proved to be repaired (Figure 4). The patient has been followed up for four years, and he is asymptomatic. The panoramic radiography and CT scan showed areas of bone formation with more intense radiopacity and no recurrence thus far (Figure 5).

\section{Discussion}

CGCLs account for $10 \%$ of all benign jaw lesions. The proportion of mandibular to maxillary involvement is $2: 1$ or 3:1 [13]. Lesions are more common in the anterior region of the jaw, and mandibular lesions frequently extend across the midline [14], as observed in our case.

Based on clinical and radiographic features, these lesions can be classified as non-aggressive and aggressive. The non-aggressive form is characterised by slow growth, typically asymptomatic growth that does not perforate the cortical bone or induce root resorption and has a low recurrence rate. Aggressive lesions are characterised by

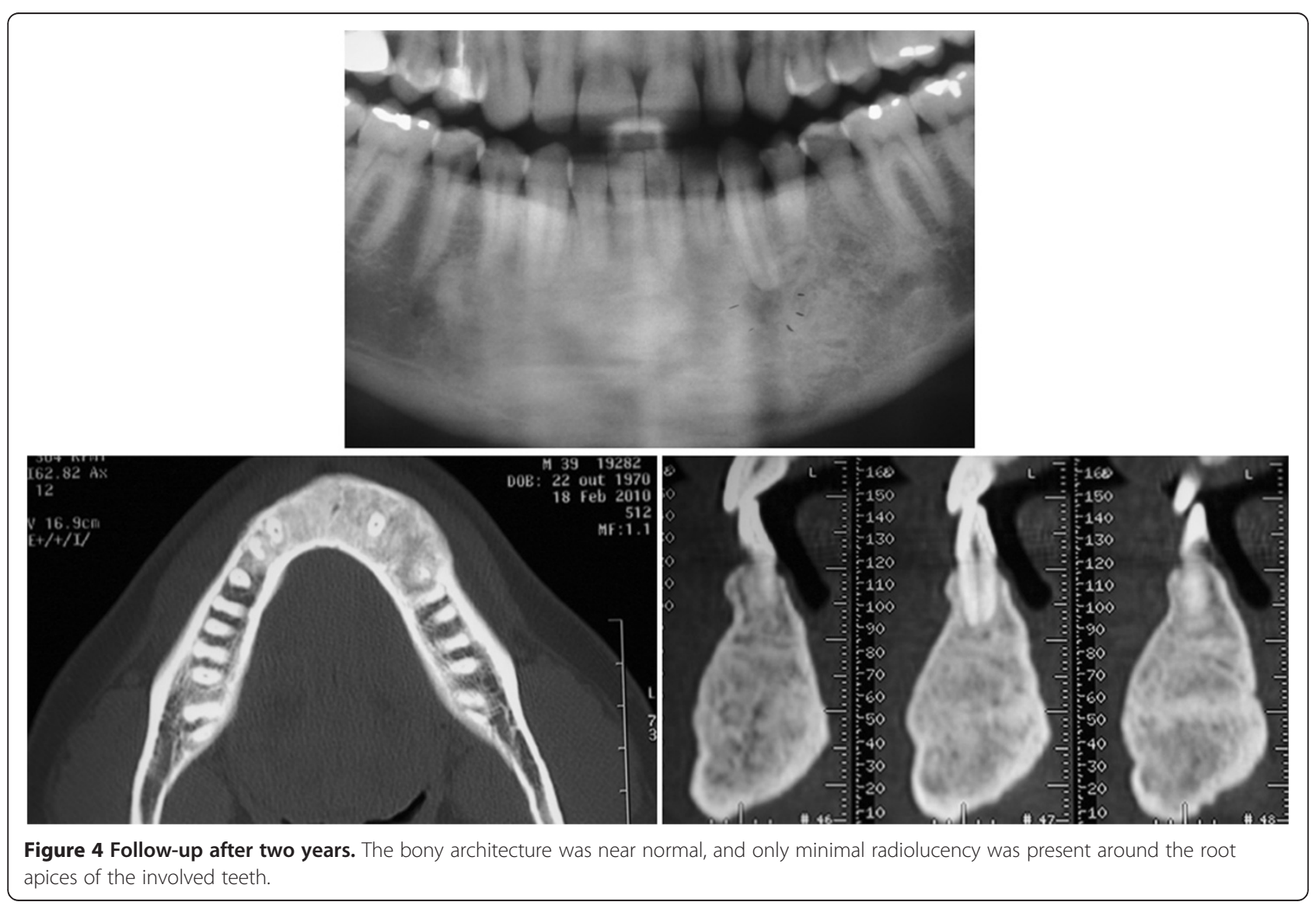




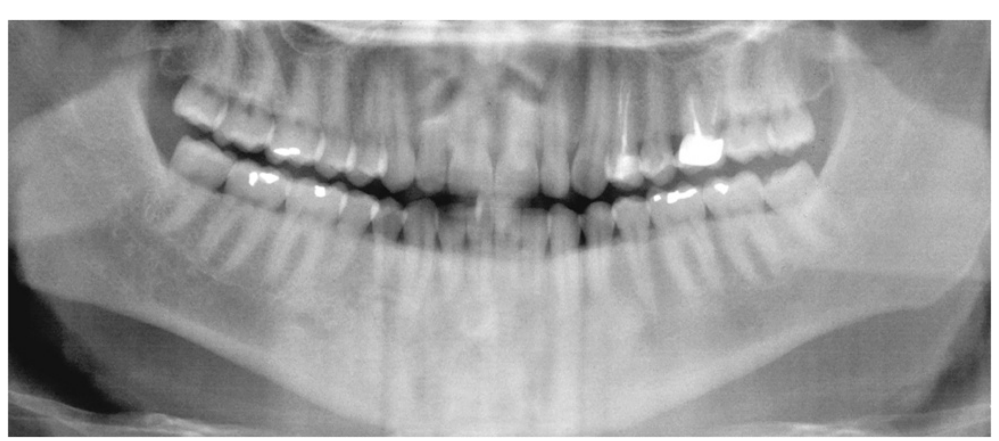

Figure $\mathbf{5}$ Follow-up after four years. Areas of new bone formation with more intense radiopacity.

pain, rapid growth, paraesthesia, root resorption, cortical perforation and a high recurrence rate after surgical treatment [5]. Although the patient did not report pain, other features of an aggressive lesion were observed, including paraesthesia, cortical perforation and root resorption.

A number of alternative nonsurgical therapies, such as intralesional corticosteroid injection, have been described for the management of CGCL. On reviewing the literature, we have found 18 reported cases that were treated with corticosteroids, with variable responses (Table 1). In the majority of the cases, six injections were administered, and the patients were followed up with periodic radiographic examination.
Steroid therapy was chosen in this case report because of the following advantages: ease of administration and lower invasiveness; relatively short duration of treatment (6 weeks average compared with 3-27 months for calcitonin and interferon- $\alpha$ ); a relatively higher success rate compared with calcitonin/interferon- $\alpha$; cost-effectiveness; availability; and minimal systemic side effects [10]. In addition, intralesional injection is preferable to systemic administration to achieve an elevated concentration of the medication in the tissue [7].

CGCL treatment is described as surgery, but the evidence of osteoclastic features enabled a change in the treatment of more aggressive cases, which tend to recur, or the

Table 1 Reported cases managed by intralesional corticosteroids injection

\begin{tabular}{|c|c|c|c|c|c|}
\hline Year & Author & No. of cases & Site & No. of injections & Time of resolution \\
\hline \multirow[t]{4}{*}{1994} & Terry and Jacoway [12] & 4 & Mandible & 6 & 3 years \\
\hline & & & Mandible & 6 & 1 year 4 months \\
\hline & & & Mandible & 6 & 2 years 2 months \\
\hline & & & Mandible & 6 & Incomplete \\
\hline 1994 & Kermer et al. [20] & 1 & Mandible & 6 & 3 years \\
\hline 2000 & Khafif et al. [21] & 1 & Maxilla & 6 & 2 years \\
\hline 2001 & Kurtz et al.[6] & 1 & Mandible & 12 & 2 years \\
\hline 2001 & Adornato and Paticoff [7] & 1 & Mandible & 6 & Partial 7 months \\
\hline \multirow[t]{4}{*}{2002} & Carlos and Sedano [8] & 4 & Maxilla & 20 & 7 years \\
\hline & & & Mandible & 17 & 6 years \\
\hline & & & Maxilla & 4 & $\begin{array}{l}\text { Residual lesion } \\
1 \text { year } 3 \text { months }\end{array}$ \\
\hline & & & Mandible & 4 & 2 years \\
\hline 2005 & Sezer et al. [9] & 1 & Mandible & 6 & 3 years \\
\hline 2005 & Abdo et al. [18] & 1 & Mandible & 3 & $11 / 2$ year \\
\hline \multirow[t]{2}{*}{2009} & Mohanty and Jhamb [10] & 2 & Mandible & 5 & $11 / 2$ year \\
\hline & & & Mandible & 6 & $11 / 2$ year \\
\hline 2010 & Shirani et al. [19] & 1 & Mandible and maxilla & 6 & 2 years \\
\hline 2011 & Rachmiel et al. [11] & 1 & Mandible & 6 & 5 years \\
\hline Total & 11 & 18 & Proportion mandible:maxilla 15:4 & Mean 7.27 & Mean $2 \frac{1}{2} 2$ years \\
\hline
\end{tabular}


cases with extensive destruction that require reconstructive surgery. In this case, the patient did not undergo surgery because he wished to preserve the nearby teeth and their vitality, to avoid endodontic treatments, and to preserve the maintenance of periodontal support and the structure of the adjacent bone.

It is well known that corticosteroids decrease blood calcium levels by suppressing intestinal calcium absorption and decreasing vitamin D activity and the reabsorption of calcium in the renal tubules [15]. In the present case, calcium carbonate was administered to facilitate the calcification of the lesion.

Bisphosphonates inhibit the formation of osteoclasts from immature precursor cells and induce the apoptosis of mature osteoclasts. Landesberg et al. [1] reported three cases of CGCLs treated with bisphosphonates with variable responses. It is evident in the two cases that the most significant regression is observed after the initial infusion of the drug. In the patient who received the drug at yearly intervals, it is difficult to determine whether higher doses and/or frequency of drug administration would have shown a more favourable result. The authors suggested that this drug might be useful as a primary or adjunctive therapy in the treatment of CGCL.

The administration of bisphosphonates in Paget's disease, bone metastases of multiple myeloma, breast and prostate cancers and osteoporosis effectively restores bone mineral density and bone strength, reduces the incidence of bone fracture and dramatically improves quality of life [16].

Although bisphosphonates are generally well tolerated, bisphosphonate exposure has been linked to osteonecrosis of the jaw (ONJ). The most important predisposing factors for this condition are the type and total dose of bisphosphonate and a history of trauma, dental surgery or dental infection. The risk is substantially higher for patients taking zoledronic acid and increases over time, likely because of the long half-life of these drugs. The degree of risk for ONJ in patients taking oral bisphosphonates, such as alendronate, for osteoporosis is uncertain and warrants careful monitoring [17].

The combination of steroids with bisphosphonates appears to be valid because the former have been widely used in the treatment of CGCL [4,9-11,18-20], whereas the latter have been used successfully in antiresorptive bone lesions, such as osteoporosis and Paget's diseases [1]. Although bisphosphonates have been successfully used to control bone resorption in various diseases $[1,16]$.

Various possibilities of treatment or drug control increased the challenge of elucidating biomolecular characteristics at the time of diagnosis. We must not forget the possibility of changes that may occur with these developments, which emphasise the importance of biomolecular analysis [5]. It is also important to remember that these treatments until then described the main targets for the control of osteoclastogenesis, which is likely the expression of a genetic mutation or a metabolic disturbance. Therefore, research should continue to identify the factor that stimulates this local osteoclastogenesis and determine the most effective treatment.

\section{Conclusion}

The treatment for CGCLs remains controversial because recurrence is possible. Although the surgical procedures are effective, they have poor aesthetic and functional results when large resections are performed. Unfortunately, in this study, the combination of alendronate with corticosteroids does not appear to have benefits in treating CGCL; however, only clinical trials with a large sample size will confirm the advantages of this association.

\section{Consent}

Written informed consent was obtained from the patient for the publication of this case report and any accompanying images. A copy of the written consent is available for review by the Editor-in-Chief of this journal.

\section{Abbreviations \\ CGCL: Central giant cell lesion; CT: Computed tomography;} ONJ: Osteonecrosis of the jaws.

\section{Competing interests}

The authors declare that they have no competing interests.

\section{Authors' contributions}

NGSJ conceived of the study and participated in its design. ASDC drafted the manuscript. ENP and FMT participated in the analysis and interpretation of data. KLO assisted with the draft and review of the manuscript. JJVP participated in the design of the study and the coordination of the draft of the manuscript. All of the authors read and approved the final manuscript.

\section{Author details}

${ }^{1}$ School of Dentistry, Federal University of Pará-UFPA, Avenida Augusto Corrêa, 01, Belém, PA 66075-110, Brazil. ²Department of Oral and Maxillofacial Pathology, School of Dentistry, Federal University of Pará-UFPA, Rua dos Mundurucus, 4487, Belém, PA 66073-000, Brazil. ${ }^{3}$ School of Dentistry, University of São Paulo-USP, Avenida Professor Lineu Prestes, 2227, São Paulo, SP 05508-000, Brazil. " Faculdade de Odontologia, Instituto de Ciências da Saúde, Universidade Federal do Pará, Avenida Augusto Corrêa, 01, Belém, PA 66075-110, Brazil.

Received: 9 February 2012 Accepted: 18 July 2012

Published: 22 August 2012

\section{References}

1. Landesberq R, Eisiq S, Fennoy I, Siris E: Alternative indications for bisphosphonate therapy. J Oral Maxillofac Surg 2009, 67:(Suppl 5)27-34

2. de Lange J, van den Akker HP, van den Berg H: Central giant cell granuloma of the jaw: a review of the literature with emphasis on therapy options. Oral Surg Oral Med Oral Pathol Oral Radiol Endod 2007, 104:(Suppl 5)603-615.

3. Nicolai $G$, Lorè $B$, Mariani $G$, Bollero $P$, de Marinis L, Calabrese L: Central giant cell granuloma of the jaws. J Craniofac Surg 2010, 21:(Suppl 2)383-386.

4. Nogueira RLM, Teixeira RC, Cavalcante RB, Ribeiro RA, Rabenhosrt SHB: Intralesional injection of triamcinolone hexacetonide as na alternative treatment for central giant-cell granuloma in 21 cases. Int J Oral Maxillofac Surg 2010, 39:(Suppl 12)1204-1210. 
5. Vered M, Buchner A, Dayan D: Central giant cell granuloma of the jawbones - new insights into molecular biology with clinical implications on treatment approaches. Histol Histopathol 2008, 23:(Suppl 9)1151-1160.

6. Kurtz $M$, Mesa $M$, Alberto $P$ : Treatment of a central giant cell lesion of the mandible with intralesional glucocorticosteroids. Oral Surg Oral Med Oral Pathol Oral Radiol Endod 2001, 91:(Suppl 6)636-637.

7. Adornato MC, Paticoff KA: Intralesional corticosteroid injection for treatment of central giant-cell granuloma. J Am Dent Assoc 2001, 132:(Suppl 2)186-190.

8. Carlos R, Sedano HO: Intralesional corticosteroids as na alternative treatment for central giant cell granuloma. Oral Surg Oral Med Oral Pathol Oral Radiol Endod 2002, 93:161-166.

9. Sezer B, Koyuncu B, Gomel M, Gunbay T: Intralesional corticosteroid injection for central giant cell granuloma: a case report and review of the literature. Turk J Pediatr 2005, 47:75-81.

10. Mohanty $S$, Jhamb A: Central giant cell lesion of mandible managed by intralesional triamcinolone injections. A report of two cases and literature review. Med Oral Patol Oral Cir Bucal 2009, 14(Suppl 2):E98-E102.

11. Rachmiel A, Emodi O, Sabo E, Aizenbud D, Peled M: Combined treatment of aggressive central giant cell granuloma in the lower jaw. $J$ Craniomaxillofac Surg 2012, 40:292-297.

12. Terry BC, Jacoway JR: Management of central giant cell lesion: an alternative to surgical therapy. Oral Maxillofac Surg Clin North Am 1994 6:579-600.

13. Kruse-Losler B, Diallo R, Gaertner C, Mischke KL, Joos U, Kleinheinz J: Central giant cell granuloma of the jaws: a clinical, radiologic, and histophatologic study of 26 cases. Oral Surg Oral Med Oral Pathol Oral Radiol Endod 2006, 101:(Suppl 3)346-354.

14. Ünal M, Karabacak T, Vayisoglu Y, Bagis HE, Pata YS, Akbas Y: Central giant cell reparative granuloma of the mandible caused by a molar tooth extraction: special reference to the manuever of drilling the surgical field. Int J Pediatr Otorhinolaryngol 2006, 70:(Suppl 4)745-748.

15. Hanamura M, Iwamoto T, Soga N, Sugimura Y, Okuda M: Risk factors contributing to the development of hypocalcemia after zoledronic acid administration in patients with bone metastases of solid tumor. Biol Pharm Bull 2010, 33:(Suppl 4)721-724.

16. Bi Y, Gao Y, Ehirchiou D, Cao C, Kikuiri T, Le A, Shi S, Zhang L: Bisphosphonates cause osteonecrosis of the jaw-like disease in mice. Am J Pathol 2010, 177:(Suppl 1)280-290.

17. Woo SB, Hellstein JW, Kalmar JR: Systematic review: bisphosphonates and osteonecrosis of the jaws. Ann Intern Med 2006, 144:753-761.

18. Abdo EN, Alves LCF, Rodrigues AS, Mesquita RA, Gomez RS: Treatment of a central giant cell granuloma with intralesional corticosteroid. Br I Oral Maxillofac Surg 2005, 43:(Suppl 1)74-76.

19. Shirani G, Abbasi AJ, Mohebbi SZ, Shirinbak I: Management of a locally invasive central giant cell granuloma (CGCG) of mandible: report of an extraordinary large case. J Craniomaxillofac Surg 2011, 39:(Suppl 7)530-533.

20. Kermer C, Millesi W, Watzke IM: Local injection of corticosteroids for central giant cell granuloma. A case report. Int J Oral Maxillofac Surg 1994, 23:366-368

21. Khafif A, Krempl G, Medina JE: Treatment of giant cell granuloma of the maxilla with intralesional injection of steroids. Head Neck 2000, 22:(Suppl 8)822-825.

\section{Submit your next manuscript to BioMed Central and take full advantage of:}

- Convenient online submission

- Thorough peer review

- No space constraints or color figure charges

- Immediate publication on acceptance

- Inclusion in PubMed, CAS, Scopus and Google Scholar

- Research which is freely available for redistribution 